\title{
Direitos flexibilizados: análise da reforma trabalhista face à proteção do trabalho da mulher
}

Flexibilized rights: analysis of labor reform in face to protect women's work

Lara Vitória Cavalcante Arruda ${ }^{1}$ Talita de Fátima Pereira Furtado Montezuma ${ }^{2}$

RESUMO: A precarização sobre as relações de trabalho imprime desafios específicos à proteção do trabalho da mulher. A correlação entre patriarcado e capitalismo articula uma assimetria de poder e de condições laborais para as mulheres. Em contextos de flexibilização de direitos, cabe investigar como as normas incorporam estes dispositivos de gênero. Assim, o presente artigo objetiva analisar alterações da reforma trabalhista diante das normas constitucionais e da necessidade de proteção especial do trabalho da mulher. De início, mostra-se uma contextualização fático-normativa acerca do surgimento dos dispositivos legalizadores da proteção do trabalho da mulher. Em segunda parte, será apresentada uma breve explanação do que seria a Reforma Trabalhista, sendo realizada uma análise constitucional acerca de algumas alterações advindas com a referida, presentes no artigo 394-A que regula o trabalho de gestantes e lactantes em ambientes insalubres e também nos dispositivos 59-A

1 Graduanda em Direito pela Universidade Federal Rural do Semi-Árido (UFERSA)CAMPUS Mossoró.

2 Professora do curso de Direito da Universidade Federal Rural do Semi-Árido. Graduada e Mestre em Direito pela Universidade Federal do Ceará. Doutoranda em Direito pela Universidade de Brasília. 
que trata da flexibilização da jornada de trabalho e 223-G relacionado ao dano extrapatrimonial. A metodologia utiliza fontes bibliográficas, documentais e estudo de ações diretas de inconstitucionalidade. Nos resultados, argumenta-se pela inconstitucionalidade das devidas normas e pela aplicação de uma perspectiva analítica crítica às formas de inserção da mulher no mercado laboral.

PALAVRAS-CHAVE: Mulher no mercado de trabalho, reforma trabaIhista, constitucionalidade.

ABSTRACT: The precariousness of labor relations puts specific challenges to the protection of the woman's work. The correlation between patriarchy and capitalism articulates an asymmetry of power and working conditions for women. In contexts of rights flexibilization, it is worth investigating how standards incorporate these gender devices. Thus, this article aims to analyze changes in the labor reform in the face of constitutional norms and the need for special labor protection of the woman. At first, it shows a factual-normative contextualization about the emergence of legalizing devices for the protection of woman's work. In the second part, it will be displayed a brief explanation of what would be the labor reform, being made a constitutional analysis about some amendments arising from this, present in article 394-A that regulates the work of pregnant and lactating women in unhealthy environments, and also in devices 59-A that deals with working hours and $223-G$ related to off-balance sheet damage. The methodology uses bibliographic and documentary sources, besides study of direct actions of unconstitutionality. In the results, is argued for the unconstitutionality of the new rules and for the application of an analytical perspective criticism of women's insertion in the labor market.

KEYWORDS: woman in the labor market, labor reform, constitucionality

\section{INTRODUÇÃO}

A inserção da mulher no mercado laboral formal promove um conjunto de deslocamentos na esfera social, econômica, política e 
cultural, mobilizando lutas pelo reconhecimento de direitos associados às condições de trabalho. Tais reivindicações inserem-se em um contexto de articulação entre patriarcado e capitalismo, que deve servir de fundo analítico para investigações sobre o tema (MIES, 2018).

Isto porque para a mulher foi atribuído o trabalho de cuidado ${ }^{3}$ social, afetivo, privado e doméstico, considerado não econômico (GAGO, 2019) dentro das fragmentações da modernidade capitalista. Esta noção patriarcal de economia confinou o cuidado ao âmbito doméstico e lhe ignorou como uma infraestrutura social invisível que sustenta e viabiliza a existência das teias da vida e do trabalho assalariado livre (GAGO, 2019). Além de visibilizar a existência do chamado trabalho reprodutivo, as recentes contribuições no campo de estudo tratam de questionar a própria divisão entre os conceitos de trabalho produtivo e reprodutivo e a lógica de produção de valor sob a economia capitalista (FEDERICI, MIES).

Este ponto é fundante para a compreensão do tema desta pesquisa de forma contextualizada nos debates contemporâneos sobre o lugar social da mulher diante das imbricações entre patriarcado, coIonialidade e capitalismo. Reconhecer os mecanismos de produção de hierarquias sociais consiste em um processo teórico que merece atenção para que não se pense que a inserção da mulher no mercado laboral formal implicou na superação dos mecanismos de produção de desigualdade e assimetria de poder, ou que a demanda por igualdade normativa seria explicativa de todas as lutas feministas, especialmente das anti-sistêmicas.

Diante de tais assimetrias, a regulação normativa das relações laborais é desafiada a responder ao contexto social em que a vio-

3 Estudos sobre gênero e cuidado atestam que a forma social com a qual o trabalho de cuidado é significado está profundamente implicado no sistema atual de sexo/gênero, de forma que não basta evidenciar o cuidado como um trabalho invisível ou incluir os homens na partilha de suas tarefas. Isto porque a divisão sexual do trabalho de cuidado não pode ser desconstruída sem alterar a própria construção da sexualidade e, com isto, os padrões de dominação masculina, redefinindo as noções de público e privado, integrando múltiplas esferas sociais e considerando as opressões sofridas pelas mulheres. Assim, observa-se que o chamado culto à domesticidade situou as mulheres em lugares de sensibilidade, reduzindo suas questões ao campo moral e reafirmando suas tarefas como particulares, distintas do mundo do trabalho e da política. (FISHER \& TRONTO, 1990) 
lência sobre os corpos femininos, a sobrecarga de trabalho e a disparidade de remuneração consistem em expressões vivas do patriarcado capitalista.

A despeito do conjunto normativo, as reformas neoliberais (ALVES, 2009) ampliam os mecanismos de precarização das relações laborais, o que impacta de forma direta e assimétrica sobre a vida e o trabalho da mulher. Neste caminho, no dia 11 de novembro de 2017, sob um cenário de conflitividade e disputa de narrativas, a Reforma Trabalhista instrumentalizada pela Lei $n^{\circ} 13.467$ entrou em vigor modificando significativamente a Consolidação das Leis do Trabalho - CLT, de maneira que alterou, extinguiu e inseriu mais de 100 artigos.

Diante desta contextualização, a pesquisa objetiva analisar as alterações da Lei $n^{\circ} 13.467 / 2017$ à luz da proteção constitucional do trabalho da mulher. De forma específica, realiza-se uma breve sistematização fático-normativa do surgimento dos dispositivos legalizadores da proteção do trabalho da mulher e que foram adotados pelo Brasil em seu ordenamento jurídico. Posteriormente, será apresentada uma breve explanação do conteúdo da reforma trabalhista no que tange ao tema. À luz do preceito constitucional que institui o direito fundamental à proteção do trabalho da mulher, analisam-se três principais alterações no campo normativo, quais sejam: a) a alteração no artigo 394-A que regula o trabalho de gestantes e lactantes em ambientes insalubres; b) a alteração no dispositivo 59-A que trata da flexibilização da jornada de trabalho; c) e, por fim, a mudança no artigo 223-G relacionado ao dano extrapatrimonial.

O trabalho segue uma estrutura descritiva analítica, haja vista a necessidade de contextualizar e narrar as alterações no campo legislativo. Do ponto de vista metodológico, a pesquisa realiza revisão de literatura do tipo seletiva (YIN, 2016, p.57), orientada pela busca de conceitos e pesquisas relacionadas ao estudo normativo realizado. A perspectiva crítica residirá na esfera analítica, mas também se fará uso de autores do cânone jurídico nacional com o objetivo de revisar o estado do campo de conhecimento e compreender as tensões internas entre a lógica jurídica constitucional e a reforma trabalhista. A revisão de literatura se complementa com análise documental, incluindo as 
ações judiciais que questionaram a matéria nos dispositivos selecionados. Assim, foram revisadas as Ações Diretas de Inconstitucionalidade $n^{\circ} 5938,5870$ e 5606 como fontes que auxiliam o cumprimento do objetivo geral da investigação.

Nos resultados, observa-se a existência de um conflito normativo entre os instrumentos que garantem a proteção do trabalho da mulher e o conteúdo da reforma trabalhista. Argumenta-se pela densidade das normas protetivas das relações laborais, gerando a inconstitucionalidade dos dispositivos regulamentadores. Além disto, no plano conceitual, esta pesquisa aponta para a tensão crítica dos dispositivos jurídico-estatais sob a ótica da interrelação entre capitalismo e patriarcado, compreendendo que a partir desta lente de reflexão será possível avançar no reconhecimento dos mecanismos e estruturas de hierarquia social que permitem a redução da proteção institucional e social às mulheres.

\section{CAMINHOS FÁTICO-NORMATIVOS PARA \\ O RECONHECIMENTO DA PROTEÇÃO DO TRABALHO DA MULHER}

Neste primeiro tópico, será brevemente apresentado o contexto em que a mulher está inserida no surgimento dos dispositivos legalizadores da proteção de seu trabalho e que foram adotados pelo Brasil em seu ordenamento jurídico.

A inserção da mulher no mercado de trabalho se deu por meio de uma complexa trajetória de transformações culturais e históricas. $\mathrm{O}$ processo histórico moderno e ocidental, movido pela associação entre capitalismo e patriarcado, imprimiu nas relações sociais o lugar doméstico da mulher, pautado na submissão à masculinidade e ao confinamento no lugar social de cuidado, afetividade e passividade. $O$ ensino das tarefas domésticas e a introjeção do casamento enquanto projeto de realização reforçava a posição da mulher, qual seja, a de casar, realizar o trabalho doméstico e procriar (OST, 2009). 
Este processo de fortalecimento das estruturas de dominação masculina não ocorreu sem resistências. FEDERICI (2017) relata o processo de perseguição, criminalização e domestificação das muIheres na transição entre o feudalismo e o capitalismo com a perseguição às "bruxas", bem como as resistências organizadas pelas mulheres ao avanço da expropriação sobre seus corpos e comunidades. Analisando o processo de cercamento europeu, a autora observa que as mulheres, com menos poder social, tinham maior dependência das terras comunais, sendo "possível dizer que as terras comunais também foram o centro da vida social das mulheres, o lugar onde se reuniam, trocavam notícias, recebiam conselhos e podiam formar um ponto de vista próprio sobre os acontecimentos" (FEDERICI, 2017, p.138). A perda da terra, o disciplinamento dos corpos e a divisão sexual do trabalho como uma hierarquia social são alguns dos elementos explicativos deste período histórico.

Ao longo dos séculos, a ideia de domesticidade sobre o trabalho feminino ponderou. O início desta transformação começa por razões associadas aos primeiros ciclos de lutas feministas e ao momento econômico. Na história mais recente, foi com a Primeira Guerra Mundial que as mulheres - de média e alta classe - passaram a trabalhar fora de casa, enquanto uma grande quantidade de homens deslocava-se para os campos de batalha.

Neste cenário, com o final da I Guerra em 1919, foi criada a Organização Internacional do Trabalho - OIT como parte do Tratado de VersaIhes, pondo um fim à Primeira Guerra Mundial. A OIT foi fundada como a única das agências do Sistema das Nações Unidas composta de representantes de governos e de organizações de empregadores e de trabalhadores, iniciando um marco de proteção internacional de direitos.

Em sua primeira Conferência a $\mathrm{OIT}^{4}$ adotou seis convenções, a primeira se referia a uma das principais reivindicações do movimento

4 A OIT é incumbida da formulação e aplicação das normas internacionais do trabalho, por meio de Convenções e Recomendações. No momento que eram ratificas por decisão soberana de um país, as Convenções passavam a fazer parte do ordenamento jurídico do supracitado. Em vista disso, o Brasil, como membro fundador da OIT e participante da Conferência Internacional do Trabalho desde sua primeira reunião, adotava suas normas. 
sindical e operário do final do século XIX e começo do século $X X$, isto é, a limitação das 22 jornadas de trabalho a 8 horas diárias e 48 horas semanais. Além disso, merece destaque a adoção de Convenções referentes à proteção à maternidade, à luta contra o desemprego, à definição da idade mínima de 14 anos para o trabalho na indústria e à proibição do trabalho noturno de mulheres e menores de 18 anos, constituindo um marco normativo de proteção específica do trabalho da mulher (OIT, 2019, online).

Entretanto, foi só durante a Segunda Guerra Mundial, em vista da diminuição da força de trabalho masculina, que a conjuntura em questão passou a sofrer fortes alterações, quando houve uma maior inclusão da mulher no mercado de trabalho a fim de suprir a redução da disponibilidade de mão-de-obra masculina. Já na década de 1940, pôde-se observar uma maior participação feminina, em vista do processo de industrialização (SCHLICKMANN e PIZARRO, 2003).

Diante desse contexto, no ano de 1943 a Consolidação das Leis do Trabalho brasileira, Decreto-Lei $n^{\circ} 5.452 / 43$ trouxe em seu texto normativo um capítulo exclusivo à proteção ao trabalho da mulher (Capítulo III), no que tange aos períodos de descanso, locais de trabalho, discriminação, período de maternidade, amamentação e trabalho noturno. No entanto, tendo em vista um cenário em que a mulher detinha de um papel doméstico na sociedade, tais modalidades eram previstas de forma restrita.

Com base neste cenário, torna-se relevante ressaltar a Convenção Internacional sobre a Eliminação de Todas as Formas de Discriminação contra a Mulher que ocorreu em 1979, como o primeiro tratado internacional que dispôs amplamente sobre os direitos humanos da mulher, prevendo a eliminação das discriminações contra a mulher (art.11.1), a igualdade do direito inalienável ao trabalho (art.11.1.a), o direito à igualdade de tratamento e remuneração (art.11.1.b), além dos direitos de proteção à saúde e segurança no trabalho, envolvendo as chamadas funções reprodutivas (art.11.1.f) e a proteção especial durante a gravidez (art.11.2.d) (ONU, 1973, online) $)^{5}$.

5 A Convenção também predispôs em seu artigo $3^{\circ}$ que: cabe aos Estados Partes tomarem em todos os domínios o político, social, económico e cultural, todas as medidas apropriadas, 
No Brasil, houve a incorporação da Convenção, mas não de forma integral, isto só veio a ocorrer no ano de 1994 com o Decreto $n^{\circ} 26$, conforme se verifica abaixo

A referida Convenção objetivou o desenvolvimento de políticas públicas voltadas para a mulher, ou seja, não se trata apenas de buscar mecanismos para que ela não seja discriminada, mas também viabilizar condições para que possa ter maiores oportunidades muna sociedade tradicionalmente machista buscando, com isso, a materialização da igualdade entre os sexos. Significa dizer que as mulheres, a partir do entendimento da Convenção, devem ser titulares de seus direitos e de suas vontades no mesmo nível que os homens. (GUERRA, 2015, P.237).

Posteriormente, entre os anos de 1964 e 1985, os mecanismos de força levaram à instauração da Ditadura Militar no Brasil, sendo responsável pela supressão de muitos dos direitos da mulher ${ }^{6}$. Porém, com crescimento e luta do movimento feminista, as centrais sindicais e os sindicatos, de acordo com Vera Soares (1998, p.41), tiveram que se abrir para a organização das trabalhadoras e incorporar questões trazidas por elas para discussões referentes ao seu cotidiano, como a desvalorização do salário, da segregação ocupacional, da ausência de infraestrutura de assistência à trabalhadora gestante, da violência no local de trabalho e também das práticas sindicais que as excluem de uma participação mais ativa nos postos de decisão.

Como consequência dessa situação nacional, no ano de 1988 a Constituição Federal ${ }^{7}$ foi promulgada, como lei suprema do Estado,

incluindo disposições legislativas, que visem assegurar o pleno desenvolvimento e o progresso das mulheres, com o fito de garantir-lhes o exercício e o gozo dos direitos do homem e das liberdades fundamentais, com base na igualdade com os homens.

6 De acordo com TELES (2015, p. 6): "A censura foi adotada desde os primeiros dias da ditadura e se manteve durante todo o período ditatorial. Aliás, a misoginia da ditadura andava de mãos dadas com a censura. Houve, de maneira especial, a censura aos assuntos referentes às mulheres, sob alegação da defesa da família, da moral e dos bons costumes."

7 Segundo AFONSO SILVA (2006, p.45): "A Constituição se coloca no vértice do sistema jurídico do país, a que confere validade, e que todos os poderes estatais são legítimos 
representando o fim da ditadura e o início de uma nova fase democrática que impactou os direitos trabalhistas da mulher. Conforme prediz Delgado (2017, p.148-149), as vantagens jurídicas atribuídas às mulheres pelo Direito são sufragadas pela Constituição que se voltou para a eliminação da discriminação de anos estruturada contra as mulheres na sociedade histórica, não só no que diz respeito ao tratamento diferenciado com relação aos homens, como também nas vantagens especificas fundada nas peculiaridades biológicas e/ ou sociológicas da mulher.

A Carta Magna outorgou uma nova posição às mulheres, haja vista as garantias de igualdade com os homens que lhe foi conferida, notoriamente com o princípio da isonomia ${ }^{8} \mathrm{e}$ seus direitos trabalhistas resguardado no artigo $7^{\circ}$. Neste sentido, apesar dos limites da norma jurídica formal, merece destaque o inciso $\mathrm{XX}$ do art.70 do texto constitucional ao dispor sobre a "proteção do mercado de trabalho da muIher, mediante incentivos específicos, nos termos da lei".

Não obstante, apesar de todas as transformações e conquistas no âmbito laboral, as mulheres ainda enfrentam constantemente condições de desigualdades laborais, como apresenta o Relatório da OIT intitulado- "Mulheres no trabalho. Tendências" de 2016, ao expor que

na medida em que elas o reconheça e na proporção por ela distribuídos. É, enfim, a lei suprema do Estado, pois é nela que se encontram a própria estruturação deste e a organização de seus órgão; é nela que se acham as normas fundamentais de Estado, e só nisso se notará sua superioridade em relação às normas jurídicas.".

8 Para o doutrinador de Direito Constitucional INOCÊNCIO MÁRTIRES COELHO (2009, p.179), o princípio da isonomia significa em síntese na ideia de tratar igualmente os iguais e desigualmente os desiguais, na medida da sua desigualdade. De modo que no texto da Constituição Federal, esse princípio é enunciado com referência à lei, isto é, todos são iguais perante a lei. Concomitantemente, José Afonso (2005, p. 211) externa ser a igualdade o símbolo fundamental da democracia, vindo a Constituição Federal de 1988 a abrir o capítulo dos direitos individuais com o princípio de que todos são iguais perante a lei, sem distinção de qualquer natureza (art. 5, caput), de modo que reforça este com muitas outras normas sobre igualdade ou buscando a igualização dos desiguais pela outorga de direitos sociais substanciais. Assim é que, já no mesmo artigo $5^{\circ}$, I, declara que homens e mulheres são iguais em direitos e obrigações. Posteriormente, no artigo $7^{\circ}, \mathrm{XXX} E \mathrm{XXXI}$, vêm regras de igualdade material, proibindo distinções fundadas em certos fatores, ao vedarem diferenças de salários, de exercício de funções e de critério de admissão por motivo de sexo, idade, cor ou estado civil e qualquer discriminação no tocante a salário e critérios de admissão do trabalhador portador de deficiência. 
"ao longo da sua vida profissional, as mulheres continuam a enfrentar obstáculos significativos no acesso a empregos dignos" (2016, p.3). A análise do problema perpassa uma crítica da ordem patriarcal capitalista, que trouxe consigo uma divisão sexual do trabalho, pautada segundo Kergoat (2003) na destinação prioritária dos homens à esfera produtiva e das mulheres à esfera reprodutiva.

Tendo tal contexto em vista, uma das maiores alterações e a mais recente que intercorreu na Consolidação das Leis Trabalhista resultando na revogação e introdução de diversos artigos foi a Lei ${ }^{0} 13.467 / 17$ (Reforma Trabalhista), na qual algumas mudanças dizem respeito à proteção aos diretos trabalhistas da mulher, tais como a possibilidade de gestantes e lactantes trabalharem em local insalubre e outros que abarcam todos trabalhadores, mas afetam principalmente a mulher, como a ampliação da jornada e a indenização por dano extrapatrimonial. Nesta pesquisa, procura-se analisar os impactos destas alterações sob a ótica constitucional.

\section{REFORMA TRABALHISTA: BREVE APRESENTAÇÃO}

No dia 23 de dezembro de 2016, foi apresentado pelo governo de Michel Temer o Projeto Lei $n^{\circ}$ 6.787/2016, intitulado como Reforma Trabalhista, com o fito alterar a Consolidação das Leis do Trabalho (CLT), aprovada pelo Decreto-Lei $n^{\circ} 5.452$, de $1^{\circ}$ de maio de 1943, e as Leis $n^{\circ} 6.019$, de 3 de janeiro de 1974, 8.036, de 11 de maio de 1990, e 8.212, de 24 de julho de 1991, tendo como objetivo apresentado, bem como disposto na redação de sua ementa a adequação da legislação às novas relações de trabalho. ${ }^{9}$

O projeto, titulado como PL 6787/2016 durante sua tramitação na Câmara dos Deputados foi aprovado por estes na madrugada do dia 27 de abril de 2017 com 296 votos a favor e 177 contrários. Seguindo

9

CAMARA DOS DEPUTADOS. PL 6787/2016. Disponível: <https://www. camara.leg.br/proposicoesWeb/fichadetramitacao?idProposicao=2122076>. Acesso: 14 de fevereiro de 2019. 
para o Senado Federal, o texto-base do Projeto de Lei da Câmara (PLC) 38/2017 foi aprovado por 50 votos favoráveis, 26 contrários e uma abstenção no dia 11 de julho de 2017, sendo sancionada pelo presidente Temer dois dias depois, sob a denominação de Lei $n^{0} 13.467$, entrando em vigor no dia 11 de novembro desse mesmo ano, complementada pela Medida Provisória 808. ${ }^{10}$

Com efeito, a Reforma Trabalhista alterou, extinguiu e inseriu mais de 100 artigos da Consolidação das Leis Trabalhistas, dentre os principais pontos modificados estão a o negociado sobre o legislado, ampliação de contratos temporários, a ampliação da jornada de trabalho, o trabalho intermitente, o parcelamento das férias, a contribuição sindical optativa, o regime de tempo parcial, imposição de multas, trabalho em locais insalubres realizados por grávidas e lactantes.

A mudança do parâmetro legislativo se dá em um cenário de endurecimento das políticas neoliberais, estimuladas para os países do Sul global a partir da década de 80 e reanimadas com maior intensidade nos últimos anos. Desta forma, os sistemas protetivos de direitos sociais e trabalhistas passam a ser descritos sob a narrativa de que são mecanismos de burocracia ou entraves à liberalidade econômica. Assim, ganha fôlego as correntes que objetivam flexibilizar os direitos conquistados:

De fato, o ramo justrabalhista afirmou-se no período anterior como o mais clássico e abrangente instrumento de políticas sociais surgido no capitalismo, produzindo inquestionável intervenção normativa na economia, em favor, regra geral, de importante distribuição social dos ganhos do sistema econômico. Nesse contexto, a desregulamentação de suas regras ou, pelo menos, sua crescente flexibilização, tudo passou a compor foco destacado na matriz cultural que se generalizou no Ocidente no último quartel do século XX. (DELGADO, 2017, P. 105) 
Diante disso torna-se relevante apontar alguns aspectos que decorreram desse processo de aprovação da reforma. De início, destaque-se a controvérsia social provocada pelo projeto, de forma que, na consulta pública disponibilizada no site oficial do Senado Federal ao longo da tramitação (SENADO, 2017, online) constatou-se que apenas 16.789 dos votos foram a favor da Reforma, ao passo que 172.166 dos demais se posicionaram contra ela ${ }^{11}$, além da existência das manifestações públicas que ocorreram por todo o país contra as reformas propostas pelo governo. ${ }^{12}$ Mesmo diante do descontentamento da população, a referida foi aprovada rapidamente, instaurando um debate em torno da legitimidade da norma. ${ }^{13}$

Além disso, ao longo de toda tramitação, a Reforma dividiu opiniões dos próprios poderes envolvidos em sua aprovação. A campanha de governo argumentava que a Reforma Trabalhista iria modernizar as leis trabalhistas no Brasil, sem que houvesse a perda dos diretos, na qual o próprio presidente declarou que "estamos dando mais um passo rumo a um Brasil de mais crescimento, empregos, e mais oportunidades", ao comemorar a aprovação do projeto (SENADO FEDERAL, 2017, web). Contudo, os oposicionistas afirmaram que a aprovação iria fragilizar as relações de trabalho "É uma farsa dizer que não tira direitos. Dá ao empregador plena

11 SENADO FEDERAL. Consulta pública. Disponível em: <https://www12.senado.leg.br/ ecidadania/visualizacaomateria?id=129049\&voto=contra>. Acesso em 16 Fev. 2019.

12 ESQUERDA DIÁRIO. Veja as manifestações por todo país contra a Reforma Trabalhista. Disponível em: <http://www.esquerdadiario.com.br/Veja-as-manifestacoespor-todo-pais-contra-a-Reforma-Trabalhista> Acesso: 18 de fev.2019.

13 Durante a redemocratização, juristas nacionais difundiram o debate em torno da legitimidade das leis, de forma que a democracia deveria ser profunda, horizontal, plural e aberta à participação, esta entendida como "a possibilidade aberta a todos de exercer a tarefa de governar, de contribuir com parcelas proporcionais para as decisões máximas, de não submeter-se senão às regras que se ajudou a elaborar e sobre as quais se deliberou. (FERRAZ JR.,1979, p.81)". Assim, seria correlata à democracia o direito de ser ouvido e levado em consideração, sendo dever do Estado disponibilizar instrumentos de consulta e formular propostas legislativas que considerem a pluralidade de interesses sociais. A partir deste marco, a Reforma Trabalhista pode ser caracterizada como uma alteração legal, porém não socialmente legítima, a despeito das controvérsias existentes e da necessidade de aprofundamento na pesquisa para se atestar metodologicamente tal consideração. 
liberdade para não assegurar os direitos dos trabalhadores", disse a deputada do Rio de Janeiro Benedita da Silva. ${ }^{14}$

Com pouco tempo de debate, com baixa densidade de instrumentos de participação, sob o desrespeito da consulta pública realizada, a alteração das leis trabalhistas foi realizada e as consequências devem ser avaliadas com o tempo. As mudanças relativas à proteção do trabalho da mulher, entretanto, foram pouco discutidas e merecem especial atenção, de forma a investigar os mecanismos pelos quais as mulheres são duplamente afetadas pela flexibilização normativa. Neste trabalho, esta pergunta mais geral aparece como pano de fundo analítico de um problema mais específico que diz respeito à (in)compatibilidade entre o marco legal e o marco constitucional.

\section{ANÁLISE DA CONSTITUCIONALIDADE DA LEI N 13.467/17 QUANTO À PROTEÇÃO AO TRABALHO DA MULHER}

Neste tópico, será realizada uma análise constitucional acerca de algumas alterações advindas com a Reforma Trabalhista relacionadas ao trabalho da mulher que levantaram maiores questionamentos, no que tange não só ao artigo 394-A que regula o trabalho de gestantes e lactantes em ambientes insalubres, mas também aos dispositivos 59-A com a jornada 12x36 e 223-G relacionado ao dano extrapatrimonial que se estendem a toda a esfera trabalhista, mas com um maior impacto para o trabalho feminino.

\subsection{DA PROTEÇÃO À MATERNIDADE}

Dentre as mudanças que a Reforma Trabalhista instituiu e que promoveu amplas discussões quanto à constitucionalidade de sua reda-

14 G1. Câmara aprova proposta de reforma trabalhista; texto segue para o Senado. Disponível em<https://g1.globo.com/politica/noticia/camara-aprova-texto-base-da-reformatrabalhista.ghtml>. Acesso em: 15 de fevereiro de 2019. 
ção ${ }^{15}$, está a do artigo 394-A. Tal dispositivo em sua anterioridade, incluído pela Lei $n^{\circ} 13.287$ de 2016 estabelecia que: "A empregada gestante ou lactante será afastada, enquanto durar a gestação e a lactação, de quaisquer atividades, operações ou locais insalubres, devendo exercer suas atividades em local salubre".

Após 14 meses, com a sanção da Lei n 13.467/17, o artigo 394-A passou a determinar explicitamente em primeiro lugar que a gestante será afastada do trabalho insalubre apenas no caso de insalubridade em grau máximo. Em segundo lugar, a trabalhadora grávida só será afastada de locais insalubres de grau médio ou mínimo quando apresentar atestado por um médico de sua confiança. Por último, as lactantes somente serão afastadas do trabalho, independentemente do grau de insalubridade, quando for apresentado por elas um atestado legitimando a sua condição. Sendo assim, houve uma diferenciação entre a gestante submetida ao grau máximo de insalubridade que será afastada automaticamente e a lactante que só terá tal possibilidade em caso de atestado médico.

A compreensão do conteúdo normativo consiste em um primeiro passo de análise. De acordo com Corrêa e Saliba (2015, p. 11-12) a palavra "insalubre" vem do latim e significa tudo aquilo que origina doença. O conceito legal de insalubridade está presente art. 189 da CLT, que prediz que atividades ou operações insalubres serão aquelas que, por sua natureza, condições ou métodos de trabalho, exponham os empregados a agentes nocivos à saúde, acima dos limites de tolerância fixados, em razão da natureza e da intensidade do agente e do tempo de exposição aos seus efeitos.

15 Para o advogado Johann Schuck (2017, web): "Veja-se que a nova Lei condicionou o afastamento da empregada gestante que atua em local insalubre em grau médio ou mínimo à apresentação de atestado médico por médico de sua confiança. (...) O que ocorre aqui é uma verdadeira violência contra a vida da mulher e do feto. Verifica-se, então, mais uma inconstitucionalidade por afronta ao direito constitucional da saúde do trabalhador, contra o direito à vida e contra o princípio da dignidade da pessoa humana. Em contraposição, a membro da Confederação Nacional da Indústria Sylvia Lorena defende a constitucionalidade ao externar que : "(...) a lei buscou trazer regulamentação que dá proteção à gestante e à lactante." 
Incumbido da tarefa de aprovar o quadro das atividades e operações insalubres e adotar normas sobre os critérios de caracterização da insalubridade pelo artigo 190 da CLT, o Ministério do Trabalho, através da Norma Regulamentadora n. 15, considera insalubre as atividades e operações que se desenvolvem acima dos limites de tolerância para ruído contínuo ou intermitente, de tolerância para ruídos de impacto, de tolerância para exposição ao calor, radiações ionizantes, limites de tolerância para poeiras minerais, condições hiperbáricas, atividades e operações envolvendo agentes químicos, que envolvem agentes biológicos, umidade e vibrações. A regulamentação graduar o adicional de insalubridade, sendo em $40 \%$ para insalubridade de grau máximo, 20\% para insalubridade de grau médio e $10 \%$ para insalubridade de grau mínimo ${ }^{16}$.

Sob essa perspectiva, deputados favoráveis à mudança defendem em entrevista à Agência Brasil (2017, web) que a garantia de integridade do feto em um ambiente classificado como de baixa periculosidade ocorre desde que a trabalhadora esteja devidamente protegida pelo uso de equipamentos de segurança individual. Entretanto, existem alertas de que o organismo materno nem sempre protege totalmente o desenvolvimento embrionário de influência ambientais adversas (PEREIRA, 2017, p. 69 apud PAUMGARTEEN, 2013, p.1486). Além disso, o uso dos equipamentos de proteção individual não blinda completamente o corpo da mulher, devendo-se considerar que a adequação na forma de uso varia conforme as regiões, o clima e o grau de vigilância da empresa.

Nesta seara, alguns questionamentos podem ser levantados quanto à literalidade da 394-A, no que diz respeito à proteção da maternidade, da saúde da mulher e consequentemente do nascituro, assegurados pela Carta Magna. Dito isto, no que tange a exigência de atestado, em sua redação anterior, a norma não Ihe exigia. Após as mudanças, bem como critica Alessandra Martins, da Associação Brasileira de Advogados Trabalhistas, a lei em seus incisos II e III transferiu para a mulher a

16 NORMA REGULAMENTADORA N. 15. Disponível em <http://www.trtsp.jus.br/geral/ tribunal2/LEGIS/CLT/NRs/NR_15.html > Acesso em: 17 de fev. de 2019. 
reponsabilidade de comprovar a necessidade de afastamento do serviço, sendo para a aludida uma regra elitista, pois:

Qual mulher pobre tem médico de sua confiança? A mulher pobre depende de um sistema de saúde que não funciona. (...) Dependendo dela apresentar ou não um atestado médico para continuar ou não em uma condição insalubre, numa negociação direta com seu empregador, onde não há nenhum tipo de paridade de armas, isso realmente representa um retrocesso colocando a mulher sob o domínio de seu empregador. (MARTINS, 2018, web)

Concomitantemente, para Raimundo Simão de Melo é possível questionar se os atestados médicos serão mesmo garantia de proteção para a mulher e o feto, já que pode ocorrer do médico não ter o conhecimento específico e necessário sobre segurança no trabalho e não deter de conhecimento concreto do local onde o ofício será exerci$\mathrm{do}^{17}$., Ainda, levando em conta apenas o número mínimo de consultas, a literatura específica aponta fatores como a baixa escolaridade, ser solteira e ser multípara associados o que implica na não realização de consultas médicas. (ROSA, SILVEIRA, COSTA, 2014, p. 977).

Destaca-se ainda que o direito a um trabalho digno e saudável está classificado como direito de segunda geração ${ }^{18}$, guiado pela dignidade da pessoa humana como fundamento do Estado Democrático de Direito (artigo 1, inciso III da CF/88). O artigo $6^{\circ}$ da Constituição traz como direitos sociais, o direito à saúde, ao trabalho, à segurança, a

17 Deve-se, ainda, considerar os casos em que as mulheres tem dificuldade de acesso à rede pública de saúde ou não realizam o pré-natal completo. Dados apontam que um terço das mulheres ainda não realizam o pré-natal completo. Disponível em: <cite https:// oglobo.globo.com/economia/um-terco-dos-bebes-nascidos-em-2016-nao-tiveram-prenatal-adequado-diz-firjan-22822787>. Acesso em: $<7$ de out. de 2019.

18 Para Paulo Bonavides (1993, p.517) "(...) são os direitos sociais, culturais e econômicos bem como os direitos coletivos ou de coletividades, introduzidos no constitucionalismo das distintas formas de Estado social, depois que germinaram por obra da ideologia e da reflexão antiliberal deste século. Nasceram abraçados ao princípio da igualdade, do qual não se podem separar, pois fazê-lo equivaleria a desmembrá-los da razão de ser que os ampara e estimula". 
proteção à maternidade e à infância. O entendimento doutrinário de Godinho Delgado corrobora o argumento:

É evidente que a Constituição não inviabiliza tratamento diferenciado à mulher enquanto mãe. A maternidade recebe normatização especial e privilegiada pela Constituição de 1988, autorizando condutas e vantagens superiores ao padrão deferido ao homem - e mesmo à mulher que não esteja vivenciando a situação de gestação e recente parto. (DELGADO, 2017, p.910)

Pode-se apontar assim, que a sujeição de mulheres grávidas ou lactantes a um ambiente de insalubridade não estaria em concordância com a proteção constitucional à maternidade, uma vez que as mulheres correm o risco de serem expostas a diversas contaminações, contraindo doenças para si e para o nascituro ${ }^{19}$, podendo este ser afetado por enfermidades de forma secundária, como nas palavras de Cruz (2013, web):

Ao longo da gravidez existe o risco de efeitos carcinogênicos após a exposição do embrião à radiação. Como é um exemplo de um efeito estocástico, não existe um limiar a partir do qual o risco é superior, significando que qualquer dose de radiação, por mais baixa que seja pode induzir a formação de células cancerígena. ${ }^{20}$

Outra questão a ser abordada é a de que a principal finalidade que teria sido utilizada para a modificação do artigo 394-A foi o aumento de postos de trabalho formais para as mulheres. Para o relator da re-

19 Raimundo Simão de Melo, Procurador Regional do Trabalho aposentado, afirma que "o trabalho de grávidas e lactantes em ambientes insalubres poderá afetar não apenas a trabalhadora, mas os recém-nascidos e mesmo os futuros seres humanos, promovendo-se com isso padrão predatório da força de trabalho já antes do nascimento dos futuros trabalhadores, quando começarão a ser atingidos por agentes contaminantes de adoecimento.". Disponível em: $<$ https://www.conjur.com.br/2017-jul-21/reflexoes-trabalhistas-reforma-erra-permitir-gravidalactante-local-insalubre>. Acesso: 17 de fevereiro.

20 Informação apresentada pela ADI 5.605 sob a referência de CRUZ, Gonçalo Pereira Rodrigues da. Radiação na gravidez: abordagem da mulher grávida exposta a radiação ionizante. Artigo de revisão bibliográfica. Mestrado integrado em medicina. Instituto de ciências biomédicas de Abel Salazar. Disponível em: <Radiacao_na_Gravidez_ Abordagem_da_Mulher_Gravida_Exposta_a_R.pdf>. 
forma, deputado Rogério Marinho (PSDB-RN) em entrevista à Agência Brasil (2017, web), em vez de proteger a gestante e o nascituro, a legislação anterior criou mais dificuldades para a mulher ingressar e permanecer no mercado de trabalho.

Não obstante, se tal situação colocar a mulher em risco de saúde em prol da atividade econômica, destaca-se uma desvalorização da dignidade e, em uma reflexão estrutural, reduz a solidariedade social e intensifica para a mulher os custos do trabalho reprodutivo. Desta forma, a medida aprofunda as desigualdades de gênero e explicita que as particularidades da reprodução da vida são reduzidas a custos econômicos que devem ser externalizados para as próprias trabalhadoras.

Além disto, do ponto de vista jurídico, o argumento em defesa da alteração legislativa pretende fundar uma dicotomia entre o direito fundamental ao trabalho e o direito fundamental à saúde e à maternidade, ao passo em que a carta constitucional compatibiliza a garantia de ambos por uma sistemática de proteção do trabalho da mulher. Com base nesta compatibilização, o artigo $7^{\circ}$ da Constituição Federal que dispõe dos direitos trabalhistas, ordena em seu inciso $X X$ sobre o dever de proteção do mercado de trabalho da mulher, mediante incentivos específicos e no inciso XXII estabelece sobre a redução dos riscos inerentes ao trabalho, por meio de normas de saúde, higiene e segurança. Paralelamente, a convenção 155 da OIT adotada pelo Brasil em 1994 dispõe acerca das obrigações no que tange a inclusão das questões de segurança, higiene e meio ambiente de trabalho em todos os níveis de ensino e de treinamento.

Em conformidade a isso, o artigo 196 da Constituição de 1988 prevê que a saúde é um direito de todos e dever do Estado ${ }^{21}$, que deve

21 A construção do conteúdo do direito à saúde remonta à década de 1970 , quando se passou a afirmar que o direito à saúde compreende dimensões mais amplas e complexas que a simples ausência de doenças. O conceito consolidou-se na $8^{\text {a }}$ Conferência Nacional de Saúde, ao dispor que "a saúde é resultante das condições de alimentação, habitação, educação, renda, meio ambiente, trabalho, transporte, emprego, lazer, liberdade, acesso e posse da terra e acesso a serviços de saúde." (Relatório final da $8^{a}$ CONFERÊNCIA NACIONAL DE SAÚDE, 1986, p. 4). A Organização Mundial de Saúde, por sua vez, afirma que a saúde é: "um estado de perfeito bem-estar físico, mental e social e não somente ausência de afecções e enfermidades" (SEGRE \& FERRAZ, 1987, online). Do 
garanti-la mediante políticas sociais e econômicas a fim de reduzir o risco de doença e de outros agravos e ao acesso universal e igualitário às ações e serviços para sua promoção, proteção e recuperação.

De par com isso, qualquer situação que envolva efetivas considerações e medidas de saúde pública (e o período de gestação e recente parto assim se caracterizam) permite tratamento normativo diferenciado [a mulher], à luz do critério jurídico valorizado pela própria Constituição da República. (DELGADO, 2017, p.910)

Deve-se considerar diante disso que a norma constitucional no artigo 170 pondera que a ordem econômica deve estar fundada na valorização do trabalho humano e na livre iniciativa de modo digno, conforme os ditames da justiça social. Nesse aspecto, em um módulo publicado pela Organização Internacional do Trabalho "Kit de Recursos sobre la Protección de la Maternidade" em 2012 foi proferido que a segurança e a saúde no período de procriação afeta todos os trabalhadores, homens e mulheres. Deste modo, os riscos no local de trabalho podem ser de natureza biológica, química ou física, podendo acarretar agravos físicos ou mentais, devido às más condições de trabalho e de um local perigoso e insalubre. Em vista disso, é cada vez mais comum abordar a questão da segurança e saúde no trabalho através do estabelecimento de políticas e procedimentos de garantia para identificar e eliminar riscos durante a gravidez.

Oportuno mencionar que a reforma altera negativamente o conteúdo jurídico do princípio protetivo ao trabalhador ${ }^{22}$, núcleo do direito

ponto de vista jurídico, a saúde é um direito de todos e dever do Estado, reconhecido na Constituição Federal de 1988. Em seu artigo $6^{\circ}$, a Constituição elenca a saúde como um direito social fundamental. No artigo 194, inclui a saúde como um dos objetivos das políticas de seguridade social. Já o artigo 196 estabelece que "A saúde é direito de todos e dever do Estado, garantido mediante políticas sociais e econômicas que visem à redução do risco de doença e de outros agravos e ao acesso universal e igualitário às ações e serviços para sua promoção, proteção e recuperação".

22 Acerca de tal norma, Godinho (2017, p. 214) prediz: "O princípio tutelar influi em todos os segmentos do Direito Individual do Trabalho, influindo na própria perspectiva desse ramo ao construir-se, desenvolver-se e atuar como direito. Efetivamente, há ampla 
do trabalho e ao princípio constitucional do não retrocesso, guiado pela proibição do legislador de suprimir de forma arbitraria a disciplina constitucional de um direito fundamental social. Por meio destas normas, infere-se que o núcleo essencial dos direitos sociais seria suficientemente garantido pelas medidas legislativas. Sobre o conteúdo jurídico do princípio, como Flávia Piovesan (2013, p. 155):

A aplicação progressiva dos direitos econômicos, sociais e culturais resulta a cláusula de proibição do retrocesso social, como também de proibição da inação ou omissão estatal, na medida em que é vedado aos Estados o retrocesso ou a inércia continuada no campo da implementação de direitos sociais.

Consoante aos argumentos expostos, a Ação Direta de Inconstitucionalidade - ADI $n^{\circ} 5938$ foi ajuizada pela Confederação Nacional dos Trabalhadores Metalúrgicos pedindo pela concessão de medida cautelar suspensiva da eficácia da expressão "quando apresentar atestado de saúde, emitido por médico de confiança da mulher, que recomende o afastamento" previsto nos incisos II e III do artigo 394-A.

A Procuradora-Geral da República, Raquel Dodge, em parecer emitido nos autos, alegou que assegurar o trabalho em ambiente salubre as gestantes e lactantes é um veículo concretizador dos direitos fundamentais ao trabalho, da proteção do mercado de trabalho das mulheres, da redução dos riscos laborais e consequentemente a de um trabalho saudável. De modo que a norma, se sustenta na errônea ideia de segurança da exposição à insalubridade, sem se atentar para singularidade, na perspectiva fisiológica, dos períodos de gestação e de aleitamento vivenciados pela mulher que trabalha ${ }^{23}$.

predominância nesse ramo jurídico especializado de regras essencialmente protetivas, tutelares da vontade e interesses obreiros; seus princípios são fundamentalmente favoráveis ao trabalhador; suas presunções são elaboradas em vista do alcance da mesma vantagem jurídica retificadora da diferenciação social prática. Na verdade, podese afirmar que sem a ideia protetivo-retificadora, o Direito Individual do Trabalho não se justificaria histórica e cientificamente."

23 AÇÃO DIRETA DE INCONSTITUCIONALIDADE. ART. 394-A-II E III DA CLT, ALTERADO PELA LEI 13.467/2017. PRELIMINAR. IMPUGNAÇÃO DE ATO NORMATIVO CUJA REDAÇÃO ORIGINAL É OBJETO DE AÇÃO DIRETA DE INCONSTITUCIONALIDADE 
Dito isto, em apreciação realizada pelo Supremo Tribunal Federal a tal ADI no dia 29 de maio de 2019, foi determinado por maioria dos votos pela procedência da ação, suspendendo consequentemente os incisos II e III do dispositivo 394-A. A sessão contava na figura de amici curiae ${ }^{24}$, os representantes da Confederação Nacional de Saúde (CNS) pela improcedência da ação, e da Central Única dos Trabalhadores (CUT), que defendeu a inconstitucionalidade da norma ${ }^{25}$.

Em divergência, o ministro Marco Aurélio votou pela improcedência da ação, sob a concepção de que os preceitos reguladores do trabalho masculino são aplicáveis ao trabalho feminino, externando que "Os preceitos encerram a liberdade da prestadora de serviços e visam atender às exigências do mercado de trabalho, para não se criar óbice à contratação de mão de obra feminina". ${ }^{26}$

ANTECEDENTE. ADI 5.605/DF. REDISTRIBUIÇÃO POR PREVENÇÃO. PROCURAÇÃO IRREGULAR. VÍCIO SANÁVEL. MÉRITO. DIREITO DO TRABALHO E DIREITO À SAÚDE. AUTORIZAÇÃO LEGAL PARA TRABALHO DE GESTANTES E LACTANTES EM AMBIENTES INSALUBRES. AFASTAMENTO CONDICIONADO À PRÉVIA E EXPRESSA RECOMENDAÇÃO MÉDICA. OFENSA A DIREITOS E PRINCÍPIOS FUNDAMENTAIS DA CONSTITUIÇÃO. ARTS. $1 .^{\circ}-I V, 6 .^{\circ}, 7 .^{\circ}-X X E$ XXII, 170, 193 E 225. CONTRARIEDADE AO COMPLEXO NORMATIVO PROTETIVO DA SAÚDE, DA MATERNIDADE E DA INFÂNCIA. ARTS. 6.․ 196, 201-II, 203-IE 227 DA CONSTITUIÇÃO. AFRONTA AOS PRINCÍPIOS DA PRECAUÇÃO, DO NÍVEL MAIS ELEVADO DE PROTEÇÃO EM MATÉRIA DE DIREITOS FUNDAMENTAIS, DA PROPORCIONALIDADE E DA ISONOMIA. RETROCESSO SOCIAL. INCONSTITUCIONALIDADE PARCIAL CONFIGURADA. PROCEDÉNCIA. Parecer $n^{\circ} 324 / 2018$ - SFCONST/PGR. Sistema Único n. ${ }^{\circ}$ 229.680/2018. AÇÃO DIRETA DE INCONSTITUCIONALIDADE 5.938/DF. SUPREMO TRIBUNAL FEDERAL. RELATOR: Ministro Alexandre de Moraes. 19/12/2018.

24 O amicus curiae é compreendido como uma figura processual que concretiza a participação e abertura do processo constitucional, ampliando a legitimidade das decisões no âmbito da jurisdição constitucional, notoriamente no controle de constitucionalidade. Oriundo do início do século XX, nos Estados Unidos, surge como instrumento de manifestação daqueles que, embora não fossem parte processual, detinham a possibilidade de apresentar um parecer jurídico ao juiz (LEAL, 2010). Ampliado para participação da sociedade civil, o amicus atualmente encontra-se disciplinado também no art.138 do vigente Código de Processo Civil brasileiro.

25 Notícias STF. Disponível em: <http://www.stf.jus.br/portal/cms/verNoticiaDetalhe.asp?id Conteudo=412571>. Acesso em: 06 de jun. de 2019.

26 Notícias STF. STF invalida norma da Reforma Trabalhista que permitia trabalho de grávidas e lactantes em atividades insalubres. Disponível em: <http://www.stf.jus.br/ portal/cms/verNoticiaDetalhe.asp?idConteudo=412571>. Acesso em: 06 de jun. de 2019. 
$\mathrm{Na}$ qualidade de relator, o ministro Alexandre de Moraes levantou alguns pontos, dentre os quais, o fato da norma impor às grávidas e às lactantes o ônus de apresentar o atestado de saúde, que de acordo com o ministro sujeita a trabalhadora a maior embaraço para o exercício de seus direitos, principalmente para as que sofrem restrições no acesso à saúde. Também arguiu que a norma está em discordância com diversos princípios constitucionais, além de ferir a dupla titularidade da mãe e da criança, assinalando ainda que o afastamento automático do local insalubre está em acordo com o entendimento do STF na proteção integral à maternidade e à saúde.

\subsection{DO AUMENTO DA JORNADA DE TRABALHO}

Outra mudança advinda da Reforma Trabalhista e passível de questionamento é o aumento da jornada de trabalho para doze horas seguidas por trinta e seis ininterruptas de descanso mediante acordo individual escrito, convenção coletiva ou acordo coletivo de trabalho, presente no artigo 59-A. O relator da Reforma Trabalhista, Rogério Marinho, afirmou na Câmara dos Deputados que "chega-se à fácil conclusão de que a jornada $12 \times 36$ é mais benéfica ao trabalhador, que labora doze horas e descansa trinta e seis horas", concluindo que "o trabalhador labora mensalmente bem menos horas que aquele que trabalha oito horas por dia". ${ }^{27}$

Se tal medida afeta toda a classe trabalhadora, as mulheres estão mais vulneráveis aos impactos negativos. Isto porque, de acordo com um levantamento do Instituto Brasileiro de Geografia e Estatística $(\mathrm{IBGE})^{28}$, foi constatado que a mulheres brasileiras trabalham, em média, oito horas a mais por semana em afazeres domésticos

27 EDITORA FORUM. Reforma trabalhista: jornada de 12 horas de trabalho por 36 de descanso - impressões iniciais do art. 59-A da CLT. Disponível em: $<$ https://www. editoraforum.com.br/noticias/reforma-trabalhista-jornada-de-12-horas-de-trabalho-por36-de-descanso-impressoes-iniciais-do-art-59-da-clt/>. Acesso em: 18 de fev. de 2019.

28 REVISTA Exame. Mulheres trabalham $72 \%$ a mais do que homens em tarefas domésticas. Disponível em: <https://exame.abril.com.br/brasil/mulheres-trabalham-73-a-mais-do-quehomens-em-tarefas-domesticas/>. Acesso em: 18 de fev. 2019. 
ou no cuidado de familiares do que os homens. Enquanto os homens gastam 10,5 horas por semana com esse tipo de tarefa, as mulheres dispendem 18,1 horas todas as semanas com o cuidado doméstico, exemplo do trabalho reprodutivo não remunerado. No Nordeste, a situação é mais dramática do que na média do país, já que os homens trabalham 10,5 horas na semana, mas as mulheres acumulam 19,5 horas, quase $80 \%$ a mais.

Tal cenário se estabelece em vista da dupla jornada que as mulheres enfrentam diariamente, operando como força de trabalho produtiva no mercado e com uma jornada doméstica em sua casa, conforme se constata em Macedo (1994, p.67) ao afirmar que as mudanças do papel da mulher na sociedade e na família também geram grandes alterações no ciclo vital da família, mas a inserção no mercado formal não eliminou a sobrecarga de trabalho doméstico.

Deve-se mencionar, ainda, que o Tribunal Superior do Trabalho já autorizava o aumento da jornada em situações excepcionais mediante a Súmula $444^{29}$, que passou a estabelecer como válido, mas em caráter excepcional, a jornada de doze por trinta e seis de descanso, prevista em lei ou ajustada exclusivamente mediante acordo coletivo de trabalho ou convenção coletiva de trabalho, assegurada a remuneração em dobro dos feriados trabalhados.

Entretanto, o artigo 59-A desatende a previsão da jornada se estender somente por acordo coletivo ou convenção coletiva ao estabelecer a possibilidade do pacto via acordo individual, desconsiderando a vulnerabilidade do trabalhador e o núcleo normativo do princípio protetivo no Direito do Trabalho. Ademais, sob a égide constitucional, o artigo 7, inciso XIII também determina a "duração do trabalho normal não superior a oito horas diárias e quarenta e quatro semanais, facultada a

29 Súmula 444/TST - 25/09/2012. Jornada de trabalho. Compensação. Convenção coletiva. Norma coletiva. Lei. Escala de 12 por 36. Validade. Feriados trabalhados. CLT, art. 59. $\mathrm{CF} / 88$, art. $7^{\circ}, \mathrm{XIII}$ e XXVI.

É valida, em caráter excepcional, a jornada de doze horas de trabalho por trinta e seis de descanso, prevista em lei ou ajustada exclusivamente mediante acordo coletivo de trabalho ou convenção coletiva de trabalho, assegurada a remuneração em dobro dos feriados trabalhados. O empregado não tem direito ao pagamento de adicional referente ao labor prestado na décima primeira e décima segunda horas. 
compensação de horários e a redução da jornada, mediante acordo ou convenção coletiva de trabalho", e não em acordo individual.

Neste sentido, a adoção das 12 horas pode ser prejudicial para a saúde física e mental do empregado, contrariando o artigo $6^{\circ} \mathrm{e}$ art. 196 da CF/88 quanto o dever do Estado em assegurar a saúde de todos. Além disto, o artigo inciso XX do artigo 7 estabelece que a proteção ao mercado de trabalho da mulher deve ocorrer por meio de incentivos específicos, o que inclui também a disposição de normas que comportem a condição vivenciada pela mulher em suas atividades extras realizadas no âmbito doméstico, conquanto ainda não se refundou uma divisão social do trabalho do cuidado baseada na responsabilização de ambos os gêneros. Desta forma, a alteração dificulta particularmente a jornada laboral feminina com a atual disposição do artigo 59-A.

Em 1992, o Brasil incluiu em seu ordenamento o Pacto Internacional sobre Direitos Econômicos, Sociais e Culturais 1966, nele o artigo $7^{\circ}$ prediz que os Estados partes do presente Pacto devem reconhecer o direito de toda pessoa de gozar de condições de trabalho justas e favoráveis. Neste plano, segundo o Ministério Público do Trabalho - MPT, a norma da reforma viola a jornada constitucional e também vai contra acordos internacionais assinados pelo Brasil, que preveem "que toda pessoa tem o direito de desfrutar de condições justas de trabalho, que garantam o repouso, os lazeres e a limitação razoável do trabalho"30. Dito isto, observa-se violação no plano normativo interno e externo.

\subsection{DO DANO EXTRAPATRIMONIAL}

A Lei $n^{0} 13.467 / 17$ alterou os instrumentos que tratam do dano extrapatrimonial nas relações de trabalho especificados no título II- A da CLT. O art. 223-C dispõe que "A honra, a imagem, a intimidade, a liberdade de ação, a autoestima, a sexualidade, a saúde, o lazer e

30 REPÓTER BRASIL. Por que a reforma trabalhista é inconstitucional. Disponível em $<$ https://reporterbrasil.org.br/2017/07/por-que-a-reforma-trabalhista-e-inconstitucional/> Acesso em: 19 de fev. 2019. 
a integridade física são os bens juridicamente tutelados inerentes à pessoa física". Já no art. 223-D, a imagem, a marca, o nome, o segredo empresarial e o sigilo da correspondência são bens juridicamente tutelados inerentes à pessoa jurídica.

A definição dos bens juridicamente protegidos encontra conformidade na tradição civilista constitucional. Entretanto, a métrica utilizada para a responsabilização sobre o dano monetarizou os bens relativos à dignidade humana em critérios hierarquizados por classes. Neste sentido, a reforma incluiu no artigo 223-G, o qual estabelece que o juiz ao apreciar o pedido de indenização considerará os seguintes parâmetros, dispostos nos incisos I ao IV respectivamente: a ofensa de natureza leve, até três vezes o último salário contratual do ofendido; ofensa de natureza média, até cinco vezes o último salário contratual do ofendido; ofensa de natureza grave, até vinte vezes o último salário contratual do ofendido; e a ofensa de natureza gravíssima, até cinquenta vezes o último salário contratual do ofendido.

O aludido dispõe de critérios acerca do valor indenizatório que deve ser pago com base no salário do ofendido, isto é, o agravo que o trabaIhador sofreu não é baseado no dano causado, mas sim em sua última remuneração. Para as empregadas, tal medida representa um retrocesso, haja vista que as mulheres ganham menos que os colegas do sexo oposto em todos os cargos, áreas de atuação e níveis de escolaridade pesquisados - a diferença salarial chega a quase $53 \%$, de acordo com uma pesquisa realizada pelo site de empregos Catho em 2018 com quase 8 mil profissionais. Ademais, foi constatado que as maiores diferenças salariais está presente entre os profissionais de nível superior e com pós-graduação, perfil em que as mulheres ganham quase a metade do salário dos homens. O percentual é atenuado conforme a escolaridade vai diminuindo, mas o salário dos homens é superior em todos os níveis de escolaridade (G1, 2018, web). ${ }^{31}$

31 G1. Mulheres ganham menos que os homens em todos os cargos e áreas, diz pesquisa. Disponível em: <https://g1.globo.com/economia/concursos-e-emprego/noticia/ mulheres-ganham-menos-que-os-homens-em-todos-os-cargos-e-areas-diz-pesquisa. ghtml> Acesso em: 14 de fev. de 2019. 
Desse modo, a mulheres que sofrem algum tipo de dano não vão deter do mesmo direito de ação reparatório que um homem, por exemplo, que for atingido por esse mesmo dano. Além disso, o artigo analisado causa uma diferença entre as próprias mulheres, bem como externa Alessandra Martins da Associação Brasileira de Advogados Trabalhistas em reportagem à Rádio Câmara (CAMARA DOS DEPUTADOS, 2018, web):

Quando se tarifa o dano moral baseado no salário e dividido em castas, uma mulher terceirizada, por exemplo, uma terceirizada e uma efetivada, que têm salários dispares, e são assediadas nas mesmas circunstâncias, pelo mesmo assediador, elas vão ter parâmetros reparatórios completamente diferentes. E isso potencializa a dor, isso potencializa a humilhação. É como se uma fosse menor do que a outra.

A Constituição de 1988 positivou os direitos humanos de personalidade, conferindo à integridade moral do indivíduo status de direito fundamental, cuja tutelados pelo art. $5^{\circ}$, incisos $\mathrm{V}$ e $\mathrm{X}$, se assentando no dever de proteção da dignidade da pessoa humana (art. 1, III- CF/88). Este também foi o entendimento da Procuradora-Geral da República:

A limitação indenizatória imposta pelo dispositivo impugnado não decorre de reserva legal prevista na Constituição, nem se ampara em 'reserva geral de ponderação', pois não decorre de conflito entre direitos fundamentais, a justificar ingerência restritiva do legislador ordinário. (DODGE, 2018, web) ${ }^{32}$

Diante disso, a ADI n 5870, proposta pela Associação Nacional dos Magistrados da Justiça do Trabalho - ANAMATRA, questiona o trecho da CLT quanto ao estabelecimento dos limites máximos a serem observados pelos juízes na fixação do valor de indenização por danos de natureza extrapatrimonial decorrentes da relação de trabalho. Para

32 FOLHA DE LONDRINA. Raquel Dodge aponta inconstitucionalidade em trechos da reforma trabalhista. Disponivel:<https://www.folhadelondrina.com.br/politica/raqueldodge-aponta-inconstitucionalidade-em-trechos-da-reforma-trabalhista-1023276.html > Acesso em: 18 de fev. 2019. 
a Associação, o predito viola artigos arts. $5^{\circ}$, inciso V, da Constituição que assegura o direito de resposta, proporcional ao agravo, além da indenização por dano material, moral ou à imagem, além do inciso $X$ que prediz serem invioláveis a intimidade, a vida privada, a honra e a imagem das pessoas, assegurado o direito a indenização pelo dano material ou moral decorrente de sua violação. Da mesma forma, foi apontada violação do art. $7^{\circ}$, inciso XXVIII, o qual dispõe o direito de um trabalho "seguro contra acidentes de trabalho, a cargo do empregador, sem excluir a indenização a que este está obrigado, quando incorrer em dolo ou culpa", o qual não restringiu a extensão da reparação pelo valor do salário do trabalhador.

O resultado final da ação pende de julgamento pelo STF, mas o conteúdo vinculado ressalta a controvérsia sobre a constitucionalidade da reforma trabalhista. Embora os parâmetros constitucionais apontados não façam específica identificação de uma norma protetiva das relações de gênero no âmbito laboral, uma compreensão sistêmica que compreenda as interrelações entre patriarcado, capitalismo e a desvalorização do trabalho feminino deve ser ampliada no âmbito acadêmico para que as repercussões específicas sobre o trabalho das mulheres possam ser analisadas em profundidade.

\section{CONSIDERAÇÕES FINAIS}

Em conformidade com os aportes empíricos e analíticos expostos, percebe-se que ao longo da história, apesar da existência de estigmas discriminatórios pautados na divisão de papéis mediante o gênero, a mulher obteve uma relevante inserção no mercado de trabalho e, com a luta feminista, instrumentos jurídicos protetivos foram incorporando as dimensões de gênero, como a Consolidação das Leis Trabalhistas, a Convenção Internacional sobre a Eliminação de Todas as Formas de Discriminação contra a Mulher, a Organização Internacional do Trabalho e a Carta Magna.

Entretanto, em termos estruturais isto não significa o rompimento entre as estruturas da exploração de classe e da opressão de gênero, as quais se articulam na reprodução combinada entre patriarcado e capitalismo. Expropriadas do chamado trabalho reprodutivo não remunerado, as mu- 
Iheres ingressam no mercado de trabalho formal em um cenário de assimetria de poder, o que se revela nos dados sobre diferenças salariais, sobrecarga de trabalho e assédio, mencionados durante esta pesquisa.

O endurecimento das relações de trabalho e a flexibilização de direitos agrava essa assimetria e põe as mulheres em processo de vulnerabilização social, o que desafia a validade e a densidade normativa das normas protetivas do trabalho. Neste âmbito, a reforma trabalhista produziu diversas transformações, dentre as quais este artigo argumenta que as alterações realizadas nos arts. 394-A, 223-G, 59-A e 394-A carregam incompatibilidades com a Constituição.

A controvérsia chegou ao STF por meio de Ações Diretas de Inconstitucionalidade e foram alvos de questionamentos e mobilizações sociais. Entretanto, os impactos específicos sobre as relações de gênero não ganharam visibilidade ampla.

Assim foi que o art. 394-A instituiu a possibilidade das gestantes e lactantes trabalharem em locais de insalubridade e virem a ser dispensadas somente com a apresentação de atestado médico, contrariando as diretrizes constitucionais dos artigos 50, 60 $7^{\circ}, 196$ e 170.

No que tange à flexibilização das doze horas por trinta e seis, não houve preocupação com o fato das mulheres realizarem uma jornada maior do que os homens, haja vista que socialmente seu trabalho ainda se configura como doméstico, o que concomitantemente pode chegar a afetar a sua saúde e a possibilidade de ter um ofício justo com condições dignas, indo de encontro com preceitos estabelecidos do artigo $6^{\circ}$, $7^{\circ}, 196$ e 170 da Carta Magna. Por fim, sobrevive o questionamento ao artigo 223-G, que precifica a dignidade dos trabalhadores em um contexto de desigualdade remuneratória entre homens e mulheres.

\section{REFERÊNCIAS}

AGÊNCIA BRASIL. Excesso de tutela estatal prejudica gestante, diz relator da reforma trabalhista. Disponível em: <http://agenciabrasil.ebc. com.br/politica/noticia/2017-05/excesso-de-tutela-estatal-prejudicagestante-diz-relator-da-reforma> Acesso em: 17 fev 2019. 
AÇÃO DIRETA DE INCONSTITUCIONALIDADE 5605. Disponível em <http://portal.stf.jus.br/processos/downloadPeca.asp?id=312352153\&ext=. pdf>. Acesso: 16 de fevereiro de 2019.

AÇÃO DIRETA DE INCONSTITUCIONALIDADE 5.938. Disponível em <https://portal.stf.jus.br/processos/downloadPeca.asp?id=1533930 7866\&ext=.pdf > . Acesso: 16 de fevereiro de 2019.

AÇÃO DIRETA DE INCONSTITUCIONALIDADE 5.870. Dispo nível:<https://portal.stf.jus.br/processos/downloadPeca. asp? id=15339307849\&ext=.pdf $>$. Acesso: 19 de fevereiro.

ALVES, Giovanni. Trabalho e reestruturação produtiva no Brasil neoliberal: Precarização do trabalho e redundância salarial. Revista Katálysis, Florianópolis, v. 12, n. 2.

BALDIVIESO, Pablo Enrique Carneiro. O trabalho da Lactante e a Reforma Trabalhista: Reflexões sobre o ar. 394-A, inciso II da CLT. Direitos sociais e políticas públicas III [Recurso eletrônico on-line] organização CONPEDI/ UFBA Coordenadores: José Sebastião de Oliveira; Saulo de Oliveira Pinto Coelho - Florianópolis: CONPEDI, 2018.

BONAVIDES, Paulo. Curso de direito constitucional. São Paulo: Malheiros, 1993. p 517.

BRASIL.SupremoTribunalFederal.Açãodiretadeinconstitucionalidade $n^{\circ}$ 3938/DF - Distrito Federal. Relator: Ministro Alexandre Moraes. 29 de maio de 2019. Disponível em: <http://www.stf.jus.br/arquivo/cms/ noticiaNoticiaStf/anexo/ADI5938EmentaeVOTO.pdf >. Acesso em: $06 \mathrm{de}$ jun. de 2019.

BRITO, Yasmin. REFORMA TRABALHISTA E O DIREITO DA MULHER: AVANÇO OU RETROCESSO?. Monografia. Universidade Federal de Pernambuco, Recife, 2017.

. BRASIL. DECRETO-LEI N. ${ }^{\circ} 5.452$, DE $1^{\circ}$ DE MAIO DE 1943. Consolidação das Leis Trabalhistas. Disponível em: <http:// www.planalto.gov.br/ccivil_03/Decreto-lei/Del5452.htm >. Acesso em 28/12/2018. 
COELHO, Giovanna, Cristina Calabresi, SCRAMIM Gustavo Rodrigo Meyer. REFORMA TRABALHISTA: PRECARIZAÇÃO DO TRABALHO FEMININO. CSOnline - Revista Eletrônica de Ciências Sociais, Juiz de Fora, n. 23 (2017), .pp. 241-262.

. Constituição (1988). Constituição da República Federativa do Brasil. Brasília, DF: 1988. Disponível em:<http://www.planalto.gov. br/ccivil_03/constituicao/constituicao.htm>. Acesso em 11/01/2019.

.CAMARA DOS DEPUTADOS. Reforma Trabalhista: a situação das mulheres - Bloco 10. Disponível em<http://www2. camara.leg.br/camaranoticias/radio/materias/REPORTAGEMESPECIAL/561199-REFORMA-TRABALHISTA-A-SITUACAO-DASMULHERES-BLOCO-10.html>. Acesso em: 17 de fevereiro de 2019.

. CAMARA DOS DEPUTADOS. PL 6787/2016. Disponível: $<$ https://www.camara.leg.br/proposicoesWeb/fichadetramitacao?idPro posicao=2122076>. Acesso: 14 de fevereiro de 2019.

DELGADO, Maurício Godinho; DELGADO, Gabriela Neves. A reforma trabalhista no Brasil: com os comentários à Lei n. 13.467/2017. São Paulo: LTr, 2017.

. Curso de Direito do Trabalho. 16. ed. rev. e ampl. São Paulo: LTr, 2017.

EDITORA FORUM. Reforma trabalhista: jornada de 12 horas de trabalho por 36 de descanso - impressões iniciais do art. 59-A da CLT. Disponível em: $<$ https://www.editoraforum.com.br/noticias/reformatrabalhista-jornada-de-12-horas-de-trabalho-por-36-de-descansoimpressoes-iniciais-do-art-59-da-clt/>. Acesso em: 18 de fev. de 2019.

ESTADÃO. Raquel aponta inconstitucionalidade em trechos da Reforma Trabalhista. Disponível em<https://politica.estadao.com.br/ blogs/fausto-macedo/raquel-aponta-inconstitucionalidade-em-trechosda-reforma-trabalhista/ > . Acesso em: 17 de fevereiro de 2019.

ESQUERDA DIÁRIO. Veja as manifestações por todo país contra a Reforma Trabalhista. Disponível em: <http://www.esquerdadiario. 
com.br/Veja-as-manifestacoes-por-todo-pais-contra-a-ReformaTrabalhista> Acesso: 18 de fev.2019.

FEDERICI, Silvia. Calibã e a bruxa: mulheres, corpo e acumulação primitiva. São Paulo: Elefante, 2017.

FERRAZ JR., Tércio Sampaio. Democracia e Participação. In: Centro de Documentação Política e Relações Internacionais (Org.), Universidade de Brasília. Curso de Introdução à Ciência Política. Brasília: Universidade de Brasília, 1979.

FISHER, Berenice; TRONTO, Joan. Toward a Feminist Theory of Caring. In Emily K. Abel and Margaret K. Nelson (eds.), Circles of Care: Work and Identity in Women's Lives. Albany: SUNY Press, 1990.

FOLHADELONDRINA. Raquel Dodge aponta inconstitucionalidade em trechos da reforma trabalhista. Disponível:<https:// www.folhadelondrina.com.br/politica/raquel-dodge-apontainconstitucionalidade-em-trechos-da-reforma-trabalhista-1023276. html > Acesso em: 18 de fev. 2019.

GAGO, Verônica. Potencia feminista. Buenos Aires: Tinta Limón, 2019.

G1. Câmara aprova proposta de reforma trabalhista; texto segue para o Senado. Disponível em<https://g1.globo.com/politica/noticia/ camara-aprova-texto-base-da-reforma-trabalhista.ghtml>. Acesso em: 15 de fevereiro de 2019.

G1. Mulheres ganham menos que os homens em todos os cargos e áreas, diz pesquisa. Disponível em: <https://g1.globo.com/ economia/concursos-e-emprego/noticia/mulheres-ganham-menosque-os-homens-em-todos-os-cargos-e-areas-diz-pesquisa.ghtml> Acesso em: 14 de fev. de 2019.

LEAL, Mônia Clarissa Henning. La noción de Constituición abierta de Peter Harbele como fundamento de uma jurisdicción constitucional abierta y como presupuesto para la intervención del amicus curiae en el derecho brasileño. Estudios Constitucionales, Año 8, N¹, 2010, pp. 283-304. ISSN 0718-0195. 
MACEDO, R.M. A família do ponto de vista psicológico: lugar seguro para crescer? Caderno de Pesquisa, n. 91, p. 62-68, 1994.

MENDES, Gilmar Ferreira. COELHO, Inocêncio Mártires. BRANCO, Paulo Gustavo Gonet. Curso de direito constitucional.. 4. ed. rev. e atual. São Patdo : Saraiva, 2009.

MELO, Raimundo Simão. Reforma erra ao permitir atuação de grávida e lactante em local insalubre. Disponível em: <https://www. conjur.com.br/2017-jul-21/reflexoes-trabalhistas-reforma-erra-permitirgravida-lactante-local-insalubre>. Acesso: 17 de fevereiro.

MIES, Maria. Patriarcado y acumulación a escala mundial. Madrid: Traficantes de Sueños, 2018.

NORMA REGULAMENTADORA N. 15. Disponível em <http://www. trtsp.jus.br/geral/tribunal2/LEGIS/CLT/NRs/NR_15.html > Acesso em: 17 de fev de 2019.

Notícias STF. STF invalida norma da Reforma Trabalhista que permitia trabalho de grávidas e lactantes em atividades insalubres. Disponível em: <http://www.stf.jus.br/portal/cms/verNoticiaDetalhe. asp?idConteudo=412571>. Acesso em: 06 de jun. de 2019.

OIT. Kit de Recursos sobre la Protección de la Maternidade. Disponível em: <http://mprp.itcilo.org/allegati/master/Master_SP.pdf> Acesso em: 17 de fevereiro de 2019.

ONU. CONVENÇÃO SOBREA ELIMINAÇÃO DETODAS AS FORMAS DE DISCRIMINAÇÃO CONTRA A MULHER. 1979. Disponível em <http://www.onumulheres.org.br/wp-content/uploads/2013/03/ convencao cedaw.pdf $>$, acesso realizado em 28.09.2019

ORGANIZAÇÃO INTERNACIONAL DO TRABALHO. Relatório da OIT Mulheres no trabalho. Tendências. Sumário. Genebra. 2016. P. 3.

PEREIRA, Maria da Conceição. VISÃO CRÍTICA DO ARTIGO 394-A DA CLT:. Proibição do trabalho da gestante ou lactante em 
ambiente insalubre. Dissertação (pós-graduação). Bel Horizonte. 2017.

PIOVESAN, Flávia. Direitos humanos e o direito constitucional internacional. $14^{\circ}$ ed., rev. e atual. - São Paulo: Saraiva, 2013.p. 155.

ROSA, Cristiane Quadrado. SILVEIRA, Denise Silva. COSTA, Juvenal Soares Dias. Fatores associados à não realização de pré-natal em município de grande porte. Rev Saúde Pública 2014.

REPÓTERBRASIL. Por que a reforma trabalhistaé inconstitucional. Disponível em <https://reporterbrasil.org.br/2017/07/por-que-areforma-trabalhista-e-inconstitucional/> Acesso em: 19 de fev. 2019.

REVISTA Exame. Mulheres trabalham $72 \%$ a mais do que homens em tarefas domésticas. Disponível em: <https://exame.abril.com.br/ brasil/mulheres-trabalham-73-a-mais-do-que-homens-em-tarefasdomesticas/> Acesso em: 18 de fev. 2019.

SALIBA, Tuffi Messias Insalubridade e periculosidade : aspectos técnicos e práticos / Tuffi Messias Saliba, Márcia Angelim Chaves Corrêa. - 14. ed. - São Paulo : LTr, 2015.

SCHUCK, Johann. As inconstitucionalidades da reforma trabalhista e as principais mudanças na vida do(a) trabalhador(a). Disponível em <http://www.slpgadvogados.adv.br/noticias/inconstitucionalidadesda-reforma-trabalhista-e-principais-mudancas-na-vida-doa>. Acesso: 17 de fevereiro de 2019.

SEGRE, Marco; FERRAZ, Flávio Carvalho. O conceito de saúde. Rev. Saúde Pública vol. 31 no. 5 São Paulo Oct. 1997.

SOARES, Gabriela; HOOGERHEIDE, Carline; PEREIRA, Everton. A Reforma Trabalhista e a proteção do trabalho da gestante no ambiente insalubre. Disponível em:<http://www.unibalsas.edu. br/wp-content/uploads/2017/01/3.-ARTIGO-TCC-GABRIELA.pdf> Acesso: 6 de janeiro de 2019. 
SILVA, José Afonso. Curso de Direito Constitucional Positivo. Malheiros, São Paulo, 2006, p. 45.

.SENADO FEDERAL. Consulta pública. Disponível em:

$<$ https://www12.senado.leg.br/ecidadania/visualizacaomateria?id=129 049\&voto=contra>. Acesso em 16 Fev. 2019.

YIN, Robert K. Pesquisa qualitativa do início ao fim. Porto Alegre: Penso, 2016.

Recebido em 30/10/2019

Aprovado em 24/01/2020 